\title{
Asphyxial Deaths in Riyadh, Saudi Arabia: A Two Years Retrospective Study
}

\author{
Mofrih M. Hegazy ${ }^{1}$, Ahmed I. Alyahya ${ }^{2}$, Abdullah M. Aldossary and Hussain S. Bahshwan ${ }^{3}$ \\ ${ }^{1}$ Forensic Medicine and Clinical Toxicology Department, Faculty of Medicine, Menoufia University, Menoufia, Egypt. \\ ${ }^{2}$ Forensic Science Department, King Fahad Security College, Riyadh, Saudi Arabia. \\ ${ }^{3}$ Forensic Medicine Center, Riyadh, Saudi Arabia.
}

All rights reserved.

\begin{abstract}
A retrospective study was carried out on 172 cases of asphyxial death autopsied at the Forensic Medicine Centre in Riyadh, Kingdom of Saudi Arabia during the period from January 2012 to December 2013. Of the 172 cases, $111(64.5 \%)$ were male and $61(35.5 \%)$ were female, with approximately $51 \%$ of the cases being male manual workers and $28.5 \%$ female housemaids; the most common age group was 21-30 years $(52.3 \%)$. Saudi nationals comprised only a small proportion of cases $(11.6 \%)$, the majority of deaths were amongst foreign workers. Suicide was the most common manner of death $(87.8 \%)$ followed by accident $(10.5 \%)$, and few homicides (1.7\%). As expected, the most common cause of death was hanging $(87.8 \%)$ followed by drowning (6.4\%), ligature strangulation (3.5\%) and chemical asphyxia, i.e., carbon monoxide poisoning (2.3\%). Alcohol, amphetamine and cannabinoids were found in $7.6 \%, 2.3 \%$ and $1.7 \%$ of cases and carboxyhaemoglobin was found in $2.3 \%$.
\end{abstract}

Keywords Asphyxial deaths, hanging, suicide, Saudi Arabia

\section{Introduction}

$\mathrm{R}$ iyadh is the capital city of the Kingdom of Saudi Arabia and includes 20 governorates with a total population of $6,167,262$ people $(24 \%$ of the Kingdom population). In this region, all medico-legal autopsies are performed by staffs of the Forensic Medicine Centre in Riyadh.

The term asphyxia is defined as "a condition caused by interference with respiration or lack of oxygen in respired air, the result of which organs and tissues are deprived of oxygen (together with a failure to eliminate carbon dioxide), causing unconsciousness or death "(Reddy, 2009).Asphyxial deaths are common in forensic practice, and it is important to determine the manner of death in these cases. Autopsy plays a major role in such deaths, as do scene investigation and the analysis of samples (Azmak, 2006). The classification of the different forms of asphyxia is far from uniform, varying from one textbook to another and from one paper to the next (Sauvageau and Boghossian, 2010). Asphyxial deaths are often classified into the following methods: strangulation (hanging, manual, ligature), suffocation (environmental or entrapment, smothering, choking, mechanical [positional, traumatic], suffocating gases), chemical asphyxia (carbon monoxide [CO], hydrogen cyanide, hydrogen sulphide), and drowning (DiMaio and DiMaio, 2001).

Gaseous suffocation refers to cases in which a gas displaces oxygen from the environment, leading to a hypoxic air mixture, while in chemical asphyxia, inhalation of gaseous compounds prevents the utilization of oxygen at the cellular level (Dolinak, et al., 2005).

\section{Aim of the work}

This study aimed to evaluate asphyxial deaths in Riyadh, Kingdom of Saudi Arabia by the retrospective analysis of the autopsy results during two years' period (from January $1^{\text {st }} 2012$ to $31^{\text {st }}$ December 2013).

\section{Subjects and Methods}

From a multi-national population of more than 6 million people in Saudi Arabia, a total of 671 cases were referred to the Forensic Medicine Centre in Riyadh for autopsy over the two-year study period. Retrospective analysis of the autopsy records indicated that 172 cases $(25.6 \%)$ of these deaths was attributed to asphyxia. 
The medico-legal examination in Riyadh is carried out by a team that includes a forensic medical examiner, forensic pathologist and a forensic toxicologist (Medicolegal Administration, 2005), and the manner of death is determined based on the information from the scene of the investigation, autopsy findings, toxicological analysis and the general prosecutor's investigation. The prosecutor is responsible for requesting an autopsy depending on the circumstances of death. (In this study, all asphyxial deaths in which autopsies were not performed were excluded).

For each of the 172 autopsied cases the age, sex, nationality, method of asphyxiation, external and internal post-mortem findings, toxicological results and manner of death were recorded, but it was not always possible to determine the religious, marital, educational or socioeconomic status, as such information were often lacking. All of the data were collected after obtaining permission from the Riyadh Forensic Medicine Centre and all personal information collected was treated confidentially. Data was tabulated and statistically analysed by SPSS (Statistical Package for the Social Science Software), Version 11 on an IBM compatible computer. (Descriptive statistics: percentage $(\%)$, mean \pm SD, median and range. Analytic statistics: Chi-square test $\left(\chi^{2}\right)$ was also carried out.to study the association between two qualitative variables, with a $\mathrm{P}$-value $<0.05$ considered to be statistically significant).

\section{Results}

Of the 671 autopsies carried out in the Riyadh Forensic Medicine Centre between $1^{\text {st }}$ January 2012 and $31^{\text {st }}$ December 2013, asphyxia was named as the cause of death in 172 cases. Table 1 shows their classification according to sex, age, nationality, occupation and manner of death. Males predominated (111 cases, 64.5\%) with a male/female ratio $1.8 / 1$. The most common age group was that $>21-30$ years (90 cases, $52.3 \%$ ), followed by $>31$ 40 years (45 cases, $26.2 \%$ ) and $>41-50$ years (24 cases, $14 \%)$. Of the younger victims there were 3 each $(1.7 \%)$ in the 0-10 and $>11-20$ years age groups, and at the other end of the scale only 7 deaths in those aged over 50 years $(4.1 \%)$.

Most deaths were in the non-Saudi population $(152,88.4 \%)$, with Saudi nationals much less represented (20 cases, $11.6 \%$ ). In terms of occupation, male manual workers predominated (88 cases, $51.2 \%$ ), followed by housemaids (49 cases, $28.5 \%$ ). There was a small number of housewives and clerks (each 3 cases, 1.7\%), and for 29 of the deaths $(16.9 \%)$ the occupation was not known.

As regard the manner of death in the 172 cases as determined following completion of the investigations. Suicide dominated (151 cases, 87.8\%), followed by accidents (18 cases, $10.5 \%)$ and homicides were far less common( 3 cases, $1.7 \%$ ).

Hanging was by far the most common asphyxial method seen, accounting for $151(87.8 \%)$ of all cases as shown in table (2). Drowning was the next (11 cases, $6.4 \%$ ), and the remainder were due to ligature strangulation (6 cases, 3.5\%) and chemical asphyxia (4 cases, $2.3 \%$ ). Almost all of the suicide asphyxial deaths were from hanging (149 cases, 98.7\%), and the other two were from ligature strangulation; there were none from drowning or chemical asphyxia (i.e., $\mathrm{CO}$ poisoning). Of the eighteen accidental deaths, $11(61.1 \%)$ were from drowning, 4 from $\mathrm{CO}$ poisoning, 2 from ligature strangulation and 1 from hanging. Finally, in the three homicidal cases, 2 were by ligature strangulation and the other was by hanging. Chi square $\left(\chi^{2}\right)$ statistical analysis of the method of asphyxia and the manner of death was highly significant $(\mathrm{P}=0.000)$.

Table (3) lists the frequency of the asphyxial method by age group. Hanging was featured in all six groups, including the youngest (0-10 years) group, but had its highest frequency in the $>40-50$ age group, constituting $95.8 \%$ of all asphyxial deaths. Next in frequency was the $>30-40$ age group $(86.7 \%)$. Ligature strangulation was seen in three groups $(0-10,>20-30$ and $>30-40)$, drowning in four $(>01-20,>20-30,>30-40$ and $>40-50)$, and $\mathrm{CO}$ poisoning in three $(0-10,>20-30$ and $>30-40)$.

Trends by gender are recorded in table (4), which shows that the proportion of hanging cases within all asphyxial deaths was similar for both sexes (male = 98 cases, $88.3 \%$, female $=53$ cases, $86.9 \%$ ). At the same time, all eleven drowning cases were male, while all six ligature strangulation victims were female. The $\mathrm{CO}$ poisoning cases were equally distributed two for each.

Observing the findings of the hanging cases in details, table (5) shows that most of cases were complete suspension (97 cases, 64.2\%), with an atypical knot position in $96.7 \%$ of all hanging cases. In a typical hanging, the knot of the ligature should be at the centre of the nape of the neck; the knot of the ligature at any site other than the nape of the neck is atypical hanging. There were 39 cases of partial suspension (25.8\%), and in 15 cases $(9.9 \%)$, the manner of suspension was not known. Of all 151 cases of hanging, the majority $(76.2 \%)$ used a slip knot, while the other $23.8 \%$ showed a fixed knot. The place of hanging was indoors in 144 cases $(95.4 \%)$ and 7 cases $(4.6 \%)$ were outdoors. As regard the material of ligature, plastic rope was used in 107 cases $(70.9 \%)$ and a piece of cloth in 37 cases $(24.5 \%)$, while a bed sheet and electric wire were used in 5 cases $(3.3 \%)$ and 2 cases $(1.3 \%)$, respectively.

As regards to the post-mortem findings of the hanging and ligature strangulation cases table (6), the direction of the ligature mark was oblique in all cases of hanging and transverse in all cases of ligature strangulation. In the hanging deaths, the ligature mark lay above the thyroid cartilage in 125 cases $(82.8 \%)$, over and above the cartilage in 21 cases $(13.9 \%)$, and below it in 5 cases $(3.3 \%)$. In the six ligature strangulation deaths, the mark was over and above the thyroid cartilage in four cases and below it in the remaining two. Contusions along the ligature mark were present in all of the strangulation cases and in $34.4 \%$ (52 cases) of the 
hanging deaths. Other injuries (hesitated wound) were found in 4 cases $(2.6 \%)$ of hanging while defensive wounds were found in 2 cases $(33.3 \%)$ of homicidal strangulation deaths. Facial congestion was a feature in all of the ligature strangulation deaths and in $23(15.2 \%)$ of hanging deaths, while petechial haemorrhage presented in 14 cases $(9.3 \%)$ of hanging and 4 cases $(66.7 \%)$ of strangulation. Dribbling of saliva from the mouth was recorded in $50(33.1 \%)$ of the hanging deaths but in none of the strangulation cases. There was discharge of semen in only two of the hanging deaths, and incontinence of urine or faeces in only four, with neither feature seen in any of the strangulation deaths. Post-mortem lividity was noted in the hands and legs of $53.6 \%$ of the hanging deaths (81 cases) and on the back in $46.4 \%$ (70). In each of the ligature strangulation deaths, lividity was on the back. Internally, in the hanging deaths, there was haemorrhage in the strap muscle in 9 cases $(6 \%)$ and a unilateral fracture of the hyoid bone in 7 cases $(4.6 \%)$ "four cases were below and three above the age of 40 years". There were tears in the internal carotid artery in 5 cases $(3.3 \%)$. In the six ligature strangulation deaths, haemorrhage in the strap muscle was present in five cases.

Drowning cases accounted for $11(6.4 \%)$ of the asphyxial deaths. All cases were in fresh water, 3 cases $(27.3 \%)$ were found in well, 6 cases $(54.5 \%)$ were in pools and 2 cases $(18.2 \%)$ were in water tanks. Typical froth of drowning from the mouth and nostril was seen in

Table 1: Demographic data of 172 asphyxial deaths

\begin{tabular}{|l|c|c|}
\hline \multicolumn{1}{|c|}{ Category } & No. & \% \\
\hline Gender & 111 & 64.5 \\
Male & 61 & 35.5 \\
Female & $1.8: 1$ & \\
Male/female & & \\
\hline Age (years) & 3 & 1.7 \\
0 -10 & 3 & 1.7 \\
$>10-20$ & 90 & 52.3 \\
$>20-30$ & 45 & 26.2 \\
$>30-40$ & 24 & 14.0 \\
$>40-50$ & 7 & 4.1 \\
>50 & & \\
Nationality & 20 & 11.6 \\
Saudi & 152 & 88.4 \\
Non-Saudi & & \\
\hline Occupation & 88 & 51.2 \\
Manual Worker & 49 & 28.5 \\
Housemaid & 3 & 1.7 \\
Housewife & 3 & 1.7 \\
Clerk & 29 & 16.9 \\
Not known & & \\
Manner of death & 151 & 87.8 \\
Suicide & 3 & 1.7 \\
Homicide & 10.5 \\
Accident & & \\
\hline
\end{tabular}

7 cases $(63.6 \%)$ and washerwoman's hands and feet were seen in 3 cases $(27.3 \%)$ after being recovered from water for more than six hours. There were associated injuries, including abrasions and bruises, in 5 cases (45.5\%).

Chemical asphyxial deaths (CO poisoning), cherry red hypostasis was seen in all cases. One case was due to a house fire and 3 cases were due to the inhalation of $\mathrm{CO}$ in a closed car. Congested edematous brain and lungs were found in all cases.

Table (7) showed toxicological analysis of the blood samples was of all asphyxial deaths. Thirteen cases (7.6\%) were alcohol related deaths with a median (range) of $57 \mathrm{mg} / \mathrm{dl}$ (16-152), 8 cases $(5.3 \%)$ were hanging death and 5 cases $(45.5 \%)$ were drowning, with a median (range) of $43 \mathrm{mg} / \mathrm{dl}$ (23-71) and $139 \mathrm{mg} / \mathrm{dl}$ (59-152), respectively. Amphetamine was detected in 4 cases $(2.3 \%)$, all of which were hanging deaths. Cannabinoids were found in 3 cases $(1.7 \%), 2$ cases from hanging deaths and one case from chemical asphyxia (1.3\% and $25 \%)$.

All cases of chemical asphyxia (2.3\%) had carboxy-haemoglobin with a median level (60.5\%) and ranged from 49 to $82 \%$.

All of the alcohol related deaths by hanging were suicidal, but were accidental in drowning deaths. A history of psychological disorders was present in 13 cases $(7.6 \%)$ of asphyxial deaths, 11 of which were hanging and 2 of which were ligature strangulation. 
Table 2: Chi square statistical analysis of the method of asphyxia and manner of death.

\begin{tabular}{|c|c|c|c|c|c|c|}
\hline \multirow{2}{*}{ Method of asphyxia } & \multicolumn{3}{|c|}{ Manner of death (172 cases) } & \multirow{2}{*}{$\begin{array}{c}\text { Total } \\
(\mathrm{n}=172) \\
\text { No }(\%)\end{array}$} & \multirow{2}{*}{$\chi^{2}$} & \multirow{2}{*}{$\mathbf{P}$} \\
\hline & $\begin{array}{c}\text { Suicide }(\mathbf{n}=151) \\
\text { No }(\%)\end{array}$ & $\begin{array}{c}\text { Accident }(\mathbf{n}=18) \\
\text { No }(\%)\end{array}$ & $\begin{array}{c}\text { Homicide }(\mathbf{n}=\mathbf{3}) \\
\text { No }(\%)\end{array}$ & & & \\
\hline Hanging & $149(98.7)$ & $1(5.6)$ & $1(33.3)$ & $151(87.8)$ & \multirow[t]{4}{*}{1.84} & \multirow[t]{4}{*}{0.000} \\
\hline Ligature strangulation & $2(1.3)$ & $2(11.1)$ & $2(66.7)$ & $6(3.5)$ & & \\
\hline Drowning & $0(0.0)$ & $11(61.1)$ & $0(0.0)$ & $11(6.4)$ & & \\
\hline $\mathrm{CO}$ poisoning & $0(0.0)$ & $4(22.2)$ & $0(0.0)$ & $4(2.3)$ & & \\
\hline
\end{tabular}

Table 3: Distribution of Asphyxiation method according to age group (172 cases)

\begin{tabular}{|l|l|l|c|c|c|}
\hline Age group (years) & $\begin{array}{c}\text { No of cases } \\
\text { No }(\boldsymbol{\%})\end{array}$ & $\begin{array}{c}\text { Hanging } \\
\text { No }(\boldsymbol{\%})\end{array}$ & $\begin{array}{c}\text { Ligature strangulation } \\
\text { No }(\boldsymbol{\%})\end{array}$ & $\begin{array}{c}\text { Drowning } \\
\text { No }(\boldsymbol{\%})\end{array}$ & $\begin{array}{c}\text { CO poisoning } \\
\text { No }(\boldsymbol{\%})\end{array}$ \\
\hline $1-10$ & $3(100.0)$ & $1(33.3)$ & $1(33.3)$ & $0(0.0)$ & $1(33.3)$ \\
\hline$>01-20$ & $3(100.0)$ & $2(66.7)$ & $0(0.0)$ & $1(33.3)$ & $0(0.0)$ \\
\hline$>20-30$ & $90(100.0)$ & $79(87.8)$ & $3(3.3)$ & $6(6.7)$ & $2(2.2)$ \\
\hline$>30-40$ & $45(100.0)$ & $39(86.7)$ & $2(4.4)$ & $3(6.7)$ & $1(2.2)$ \\
\hline$>40-50$ & $24(100.0)$ & $23(95.8)$ & $0(0.0)$ & $1(4.2)$ & $0(0.0)$ \\
\hline$>50$ & $7(100.0)$ & $7(100.0)$ & $0(0.0)$ & $0(0.0)$ & $0(0.0)$ \\
\hline
\end{tabular}

Table 4: Chi square statistical analysis of distribution of the method of asphyxia according to gender.

\begin{tabular}{|l|c|c|c|c|c|c|c|}
\hline Gender & $\begin{array}{c}\text { No of cases } \\
\text { No }(\boldsymbol{\%})\end{array}$ & $\begin{array}{c}\text { Hanging } \\
\text { No (\%) }\end{array}$ & $\begin{array}{c}\text { Ligature strangulation } \\
\text { No (\%) }\end{array}$ & $\begin{array}{c}\text { Drowning } \\
\text { No }(\boldsymbol{\%})\end{array}$ & $\begin{array}{c}\text { CO poisoning } \\
\text { No }(\boldsymbol{\%})\end{array}$ & $\chi^{2}$ & P \\
\hline Male & $111(100.0)$ & $98(88.3)$ & $0(0.0)$ & $11(9.9)$ & $2(1.8)$ & 17.3 & 0.001 \\
\hline Female & $61(100.0)$ & $53(86.9)$ & $6(9.8)$ & $0(0.0)$ & $2(3.3)$ & & \\
\hline
\end{tabular}

Table 5: Characteristics of the hanging deaths (151 cases)

\begin{tabular}{|l|l|l|}
\hline \multicolumn{1}{|c|}{ Feature } & No & \% \\
\hline Degree of suspension & & \\
Complete & 97 & 64.2 \\
Partial & 39 & 25.8 \\
Undetermined & 15 & 9.9 \\
\hline Position of knot & & \\
Typical & 5 & 3.3 \\
Atypical & 146 & 96.7 \\
\hline Type of knot & & \\
Fixed knot & 36 & 23.8 \\
Slip knot & 115 & 76.2 \\
\hline Place of hanging & & \\
Indoor & 144 & 95.4 \\
Outdoor & 7 & 4.6 \\
\hline Type of ligature & & \\
Plastic rope & 107 & 70.9 \\
Piece of cloth & 37 & 24.5 \\
Bed sheet & 5 & 3.3 \\
Electric wire & 2 & 1.3 \\
\hline
\end{tabular}


Table 6: Distribution of post-mortem findings in hanging and ligature strangulation deaths

\begin{tabular}{|l|l|l|l|l|}
\hline \multirow{2}{*}{ Post-mortem findings } & \multicolumn{2}{|c|}{$\begin{array}{c}\text { Hanging } \\
\text { (n=151) }\end{array}$} & \multicolumn{2}{|c|}{$\begin{array}{c}\text { Ligature strangulation } \\
\text { (n=6) }\end{array}$} \\
\cline { 2 - 5 } & No & \% & No & \% \\
\hline Direction of ligature mark & & & & \\
$\quad$ Oblique & 151 & 100.0 & 0 & 0.0 \\
Transverse & 0 & 0.0 & 6 & 100.0 \\
\hline Site of ligature mark & & & & \\
$\quad$ Above thyroid cartilage & 125 & 82.8 & 0 & 0.0 \\
Over and above cartilage & 21 & 13.9 & 4 & 66.7 \\
Below cartilage & 5 & 3.3 & 2 & 33.3 \\
\hline Other findings on neck & & & & \\
$\quad$ Contusion along ligature mark & 52 & 34.4 & 6 & 100 \\
Other injuries & 4 & 2.6 & 2 & 33.3 \\
\hline Facial signs & & & & \\
Facial congestion & 23 & 15.2 & 6 & 100.0 \\
Petechial haemorrhages & 14 & 9.3 & 4 & 66.7 \\
\hline Other external findings & & & & \\
Dribbling of saliva & 50 & 33.1 & 0 & 0.0 \\
Discharge of semen & 2 & 1.3 & 0 & 0.0 \\
Urinary or faecal incontinence & 4 & 2.6 & 0 & 0.0 \\
\hline Post-mortem lividity & & & & \\
In hands and legs & 81 & 53.6 & 0 & 0.0 \\
On back & 70 & 46.4 & 6 & 100 \\
\hline Internal findings & & & & \\
Fracture of hyoid bone & 7 & 4.0 & 0 & 0.0 \\
Fracture of thyroid cartilage & 0 & 0.0 & 0 & 0.0 \\
Haemorrhage in Strap muscle & 9 & 6.0 & 5 & 83.3 \\
Carotid artery tears & 5 & 3.3 & 0 & 0.0 \\
\hline
\end{tabular}

Table (7): Distribution of toxicological analysis in asphyxial deaths in Riyadh, Saudi Arabia.

\begin{tabular}{|c|c|c|c|c|c|c|c|c|}
\hline \multirow{2}{*}{ Toxicological analysis } & \multicolumn{2}{|c|}{ Hanging $(n=151)$} & \multicolumn{2}{|c|}{ Drowning $(n=11)$} & \multicolumn{2}{|c|}{ Chemical asphyxia $(n=4)$} & \multicolumn{2}{|c|}{ Total $(n=172)$} \\
\hline & No & $\%$ & No & $\%$ & No & $\%$ & No & $\%$ \\
\hline Alcohol & 8 & 5.3 & 5 & 45.5 & 0 & 0.0 & 13 & 7.6 \\
\hline Amphetamine & 4 & 2.6 & 0 & 0.0 & 0 & 0.0 & 4 & 2.3 \\
\hline Cannabinoids & 2 & 1.3 & 0 & 0.0 & 1 & 25.0 & 3 & 1.7 \\
\hline Carboxyhaemoglobin & 0 & 0.0 & 0 & 0.0 & 4 & 100.0 & 0 & 0.0 \\
\hline
\end{tabular}

\section{Discussion}

Asphyxial deaths are caused by the failure of cells to receive and/or use oxygen (DiMaio and DiMaio, 2001).Asphyxial deaths constitute $25.6 \%$ of all forensic autopsies in Riyadh city.

In this study, males were predominant over females in asphyxial deaths, with a male to female ratio of 1.8:1. Males and females are both exposed to stress but it seems that in our societies, males are dominating and having more exposure to the external environment. This coincides with Gargi et al. (1992) and so PatelAnkur et al. (2013) who reported that males are the most common victims of violent asphyxial deaths, with a male to female ratio $1.69: 1$.

The present study revealed that males predominated in hanging over females $(64.9 \%$ cases versus $35.1 \%$ cases), as this type of asphyxiation is not the commonly chosen method of suicide by females. Of all the cases of ligature strangulation found in females, two of them were suicidal and were arrested in police stations. Both had a history of suicidal attempts and psychological disorders. We think that this was due to the unavailability of other methods and tools for suicide.

Drowning was found only in male work accidents. Chemical asphyxia deaths were equal in both males and females. These results were nearly consistent with two Indian studies (Patel-Ankur et al. 2013 and Amandeep 2003) that reported that males predominate both in hanging and drowning. Chaurasia et al. (2012) found that hanging and ligature strangulation were more prevalent among males in comparison to females.

This study revealed that the majority of asphyxial deaths were in the $>20-30$ years age group $(52.3 \%)$, followed by the $>30-40$ years age group (26.2\%). This young adult group is the most active group 
of the population and more exposed to and react with the external environment and stress and strain of life. This may be also because this is the mean age range of foreign laborers in Saudi Arabia. Another study conducted on suicidal hanging deaths in Dammam, Saudi Arabia revealed that the highest number of victims was in their fourth decade $(36.09 \%)$, followed by the third decade (28.57\%) (Al Madni et al., 2010). Our results coincided with an Indian study that found the maximum number of asphyxial deaths $(57.0 \%)$ in the $21-31$ age group followed by the 31-41 yearsage group (16\%)(Sharma, et al., 2008). Similar results were obtained by Chaurasia et al. (2012) where the 21-30 years age group constituted the most common age of asphyxial deaths $(35.79 \%)$, but the second age group was from 11-20 years (20.3\%).

As regard to nationality, the highest number of victims of asphyxia in this study were non-Saudi $(88.4 \%)$, while Saudis comprised $11.6 \%$. Most asphyxial deaths were suicide. This could be attributed to the higher standard of living and work of Saudi citizens, as well as the dominant community condemns suicidal acts and follow obeying religious prohibition, which might have a great role in decreasing this rate. Additionally, foreign labourers were exposed to more stress, which coincides with Al Madni et al. (2010).

Manual workers constituted about half of the victims of asphyxial deaths in this study (51.2\%), followed by housemaids $(28.5 \%)$. This is in line with AlMadni et al. (2010) who reported an increasing stress and strain in daily life of these persons. In the same context, a Hungarian study found that suicide was less frequent among persons with an intellectual occupation (Jegesy et al., 1995).

Suicidal manner of death, in this study, was the most common $(87.8 \%)$, followed by accidental $(10.5 \%)$ and homicidal $(1.7 \%)$ deaths. Suicide rates and various epidemiological data on suicides have become a major issue in many countries (Diekstra, 1993). These results are in agreement with Patel-Ankur et al. (2013) who found that the manner of asphyxial deaths were suicide (86.6\%), accident (10.3\%) and homicide (3.1).Most hangings were suicides $(98.7 \%)$ in this study. This result is in agreement with the findings of Madadin et al. (2013) study. Similarly, hanging is a leading method of suicide in many countries, including Germany and Japan, and it is the second-leading suicidal method after intoxication in India (Joseph et al., 2003, Ojima et al., 2004 and Wiesner, 2004). In the U.S.A, despite the fact that suicide patterns differ by state, hanging was reported to be the second most reported method of suicide after firearms in general (Shields et al., 2005). The popularity of this lethal method, especially between foreigners, may be one of the underlying causes for its use in committing suicide, as well as the lower availability of other lethal methods due to firm policies about possessing personal handguns(Al Madni et al., 2010).There was only one case of accidental hanging and one case of homicidal hanging in our study, and Cook et al.(1995) reported that accidental hanging is uncommon and constitutes nearly $5 \%$ of all hanging cases and that homicidal hanging deaths are extremely rare, whereas some studies reported homicide both in children and in adults who had a mental disease, physical weakness, or were in a state of drunkenness(Puschel et al., 1984 and Vieria et al., 1988).However, a retrospective study in Turkey demonstrated that homicidal hanging is virtually nonexistent and that all deaths in drowning and chemical asphyxia were accidental in nature. On the other hand, 2 cases $(33.3 \%)$ of ligature strangulation were accidental, while 2 cases $(33.3 \%)$ of ligature strangulation were homicides and constituted $66.6 \%$ of homicides in this study, which is in line with the Azmak (2006) study which found 2 cases $(50 \%)$ of ligature strangulation that were homicides and $2(50 \%)$ accidents.

As regards the method of asphyxiation in this study, hanging was the dominant method (87.8\%), followed by drowning $(6.4 \%)$, ligature strangulation $(3.5 \%)$ and chemical asphyxiation (CO) (2.3\%). These results coincided with a Turkish study (Azmak, 2006) where hanging constituted $41.8 \%$ of asphyxiation, drowning $30.5 \%$, ligature strangulation $2.9 \%$ and chemical asphyxia (CO) $8.2 \%$. An Indian study (Chaurasia et al., 2012) reported that hanging constituted $52.1 \%$, drowning $45.2 \%$ and ligature strangulation $2.21 \%$. Additionally, in a Pakistani study (Tirmizi et al., 2012) hanging represented $36.48 \%$ of cases of asphyxia, drowning $32.43 \%$ and ligature strangulation $16.21 \%$, and in another Pakistani study (Khalil et al., 2014) ligature strangulation was the most common type of asphyxia $(69.2 \%)$, followed by smothering $(10.8 \%)$, while hanging and drowning represented (3.8\%) and $(2.3 \%)$, respectively. The low percentage of drowning cases may be explained by the absence of rivers, seas or canals in the Riyadh region and the fact that not all drowning deaths are autopsied due to the absence of a criminal suspect.

In the present study, $25.8 \%$ of the victims were in a partial hanging position and $(64.2 \%)$ were found fully suspended with their feet clearly off the ground. These findings were inconsistent with Patel-Ankur et al. (2013) who reported that only $1.25 \%$ of the victims were in a partial hanging position. Similarly, Vijaynath et al. (2009) has reported that $5.9 \%$ of hanging victims were partially suspended while $94.1 \%$ were completely suspended. The present study reported that $9.9 \%$ of cases were undetermined suspension because the victim's original position was changed before the arrival of crime scene investigators. We recorded $3.3 \%$ of cases with typical hanging, which was in agreement with PatelAnkur et al. (2013) who reported typical hanging in $2.5 \%$ of victims. This result was inconsistent with the study byVijaynath et al. (2009) which found that $23.52 \%$ of hanging cases were typical. Additionally, Saiyed and Modi (2013) reported that $17.56 \%$ were typical hanging cases in their study. Fixed knots in the present study constituted $23.8 \%$ of hangings, while a running noose 
represented $76.2 \%$. Patel-Ankur et al. (2013) recorded that $46.25 \%$ of hanging had fixed knot and $53.75 \%$ had a running noose(Sharma et al., 2008)reported $58.78 \%$ cases of hanging with a fixed knot and $41.22 \%$ with a slip knot. Most of the hanging deaths $(95.4 \%)$ were found indoors, which is consistent with Azmak (2006) study.

In the present study, asphyxial signs (facial congestion and petechial haemorrhage) were common in strangulation deaths compared to hanging deaths. Postmortem lividity found on the back in $46.4 \%$ of hanging deaths, possibly reflecting the short time the person had remained in an upright position before being discovered by relatives. Post-mortem lividity was found on the back in all cases of ligature strangulation. Although the percentage of hyoid bone fracture in asphyxia by compression of the neck was cited by many authors as none, less or controversial, they agree that a hyoid bone fracture occurs after the age of 40 years (as it ossifies at 40 years of age). The incidence varies greatly from 0 $68 \%$ from author to author. The present study recorded fractures of the hyoid bone in $4.6 \%$ of hanging cases, which was nearly the same as the study by Vijaynath et al. (2009) which noted these fractures in $3.36 \%$ cases. Fracture of the hyoid bone may be present in young individuals. We found a fracture of the hyoid bone in $57.1 \%$ of hanging cases in individual below the age of 40 years, and Simonsen (1988) observed a fracture of the hyoid bone in $30 \%$ of hanging cases aged less than 40 years. Although most of the previous studies state that fractures of the thyroid cartilage were more common than fractures of the hyoid bones in hanging deaths (Paparo and Siegel 1984; Green et al., 2000 and Nikolic et al., 2003) there were no fractures of the thyroid cartilage in this study. This coincides with the Elfawal and Awad (1994) study. This variation might depend on the composition, multiplicity and tightness of the ligature, material used, suspension time and type of hanging.

Ethyl alcohol in the present study was detected in $5.3 \%$ of hanging cases, which explains that alcohol may play a role in amelioration of the distress associated with committing suicide. A history of psychological disorders, including psychosis, mood disorders and anxiety disorders, was present in $7.6 \%$ of hanging deaths. They might increase the risk of suicidal behaviour as reported by Pompili et al.(2010).

Similar results were obtained by Al Madni et al. (2010) and Madadin et al. (2013) where ethyl alcohol was detected in the blood of $6.76 \%$ and $5.56 \%$ of hanging cases, respectively, while $(11.9 \%)$ of hanging cases were found to have the presence of ethyl alcohol in a Turkish study in Istanbul(Uzün et al., 2007). This difference can be explained by religious and cultural backgrounds because alcohol beverage trading, manufacturing, and consumption are prohibited in the Kingdom of Saudi Arabia (KSA) and severe penalties against abusers and traders are carried out under the law. Similar results were found in the Turkish study for other substances (amphetamines in $3.96 \%$ and cannabinoids in $1.587 \%$ of cases). Murphy (2000) stated that increased suicide rates have been reported because of alcohol dependence and abuse, opiate dependence and abuse, and cannabis dependence. He also stated that drowning is sometimes the consequence of the effects of alcohol. In agreement of this, alcohol was detected in 5 cases $(45.5 \%)$ of drowning in the present study.

One of the limitations of the current study was that asphyxial deaths were studiedin onecentre in Riyadh, Saudi Arabia, but this centre receives cases referred from 20 governorates within the Riyadh region, which include more than one fourth of the total population of Saudi Arabia. Another limitation was the small sample size of asphyxial deaths that might lead to inaccurate results. This might be the underestimation of asphyxial deaths, as not all cases of asphyxial deaths were autopsied.

\section{Conclusions and recommendations}

Asphyxia is one of the important causes of death referred to the Forensic Medicine Centre in Riyadh, Saudi Arabia. Most of the asphyxial deaths in this study were due to suicidal hanging among foreign labourers and maids. Males in the third decade of life are more vulnerable victims of asphyxial deaths.

We recommend more studies to be carried out in the future to clarify these results on a larger sample in a different region in KSA over many years, and to complete autopsies for all asphyxial deaths referred to the Forensic Medicine Centres. We also support previous studies that suggest the psychological assessment of foreign labourers and maids before employment in KSA, and on a regular basis during their stay.

\section{References}

Al Madni OM1, Kharoshah MA, Zaki MK et al., (2010): Hanging deaths in Dammam, Kingdom of Saudi Arabia. J Forensic Leg Med. ; 17(5):265-8.

Amandeep S(2003): A study of demographic variables of violent asphyxialdeath : Journal of Punjab Academy of Forensic Medicine and Toxicology.;3:32-4.

Azmak D (2006). Asphyxial deaths: A retrospective study and review of the literature. American Journal of Forensic Medicine and Pathology;27(2):134- 44.

Chaurasia N, Pandey SK and Mishra A (2012): An Epidemiological Study of Violent Asphyxial Death in Varanasi Region (India) a Killing Tool. J Forensic Res;3:174.

Cooke CT, Cadden GA andMargolius KA (1995): Death by hanging in Western Australia.Pathology; 27: $268-72$.

Diekstra RFW (1993): The epidemiology of suicide and parasuicide. ActaPsychiatrScand;37: 9-20.

DiMaio DJ and DiMaio VJM (2001).Asphyxia, Forensic Pathology. $2^{\text {nd }}$ ed, CRC Press:229-399. 
Dolinak D, Matshes E and Lew E (2005): Forensic pathology: principles and practice, $1^{\text {st }}$ ed. Academic Press; 203-8.

Elfawal MA and Awad OA (1994): Deaths from hanging in the eastern province of Saudi Arabia. Med Sci Law:307-12.

Gargi J, Gorea R K, Chanana A, Mann G(1992): Violent asphyxial deaths. Journal of Indian Academy of Forensic Medicine;12(4):171-6.

Green H, James RA, Gilbert JD et al., (2000): Fractures of the hyoid bone and laryngeal cartilages in suicidal hanging. J Clin Forensic Med;7: 123126.

Jegesy A, Hrsanyi L and Angyal M(1995): A detailed study on suicides in Baranya country (Hungary). Int J Legal Med; 108(3): 150-3.

Joseph, A., Abrajam, S., Muliyil, J.P., et al., (2003): Evaluation of suicide rates in rural India using verbal autopsies, 1994-1999. BMJ;326: 1121-2

Khalil ZH, Naeem M, Adil M, et al., (2014): Asphyxial deaths: a four year retrospective study in Peshawar. J Postgrad Med Inst; 28(1):24-6.

Madadin M, Mahmoud A, Alsowaygh K, et al., (2013): Suicide deaths in Dammam, Kingdom of Saudi Arabia: Retrospective study. Egyptian Journal of Forensic Sciences;3: 39-43.

Medicolegal Administration (2005): Job description of forensic medical examiners, Guide of instruction for forensic medical examiners in Saudi arabia. $1^{\text {st }}$ ed. Riyadh: Ministry of Health Publishing, KSA: 19-40.

Murphy GE (2000). Psychiatric aspects of suicidal behaviour: Substance abuse. In: Hawton K, van Heeringen K, editor. The International Handbook of Suicide and Attempted Suicide. John Wiley \& Sons, Chichester: 107-120.

Nikolic S, Micic J, Atanasijevic T, et al., (2003): Analysis of neck injuries in hanging. Am J Forensic Med Pathol.;24:179-182.

Ojima T, Nakamura Y and Detels R (2004): Comparative study about methods of suicide between Japan and the United States J Epidemiol;19 (9): 823-9

Paparo GP and Siegel H (1984): Neck markings and fractures in suicidal hangings. Forensic Sci Int.; 24(1):27-35

Patel-Ankur P, Bhoot-Rajesh R, Patel-Dhaval J, et al., (2013). Study of Violent Asphyxial Death.
International Journal of Medical Toxicology and Forensic Medicine;3(2): 48-57.

Pompili M, Serafini G, Innamorati M et al., (2010): Suicidal Behaviour and Alcohol Abuse). Int $\mathrm{J}$ Environ Res Public Health;7(4): 1392-1431.

Puschel K, Holtz W, Hildebrand E, et al., (1984). Hanging: suicide or homicide? Arch Kriminol; 174: $141-153$.

Reddy K S N (2009): The essential of forensic medicine and toxicology, K. Sugunadevi, $28^{\text {th }}$ edition;299333.

Saiyed MZ and Modi KA (2013): Retrospective study of post-mortem cases of hanging - A method of suicide. NHL J. Medical Sciences;2: 48-50.

Sauvageau A and Boghossian E (2010): Classification of asphyxia: the need for standardization. J Forensic Sci;55(5):1259-67.

Sharma BR, Harish D, Sharma A, et al., (2008): Injuries to Neck Structures in Deaths Due to Constriction of Neck, with a Special Reference to Hanging. J Forensic Leg Med;15: 298-305.

Shields LB, Hunsaker DM andHunsaker JC (2005): Suicide: a ten-year retrospective review of kentucky medical examiner cases $\mathrm{J}$ Forensic Sci;50 (3): 613-7

Simonsen J (1988): Pathoanatomic finding in neck structures in asphyxiation due to hanging: a survey of 80 cases. Forensic Sci. Int.; 38:83-91.

Tirmizi SZ, Mirza FH and Paryar HA (2012): Medicolegal investigation of violent asphyxial deaths - an autopsy based study. J Dow Uni Health Sci.;6(3):86-90.

Uzün I, Büyük Y andGürpinar K (2007): Suicidal hanging: fatalities in Istanbul retrospective analysis of 761 autopsy cases J Forensic Leg Med; 14 (7):406-409

Vieria DN, Pinto AE and Sa FO (1988): Homicidal hanging. Am J Forensic Med Pathol;9: 287-9.

Vijaynath V, Anitha MR and RajanK(2009): A study of autopsy profile in cases of hanging. Journal of Forensic Medicine and Toicology;26(1):34-36.

Wiesner G(2004): Suicidal methods: a comparison between East and West Germany epidemiological, forensic and sociomedical aspects.

BundesgesundheitsblattGesundheitsforschungG esundheitsschutz;47 (11): 1095-106. 


\section{الملخص العربح}

\section{وفيات الاختناق في الرياض بالمملكة العربية السعودية: دراسة مرجعية لمدة عامين}

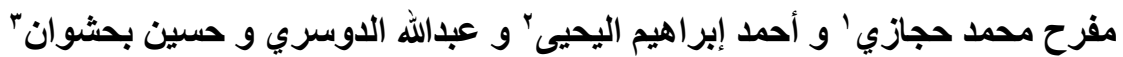

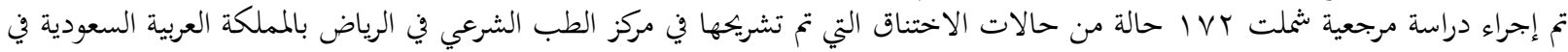

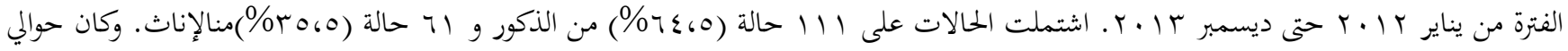

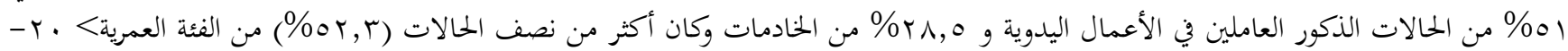

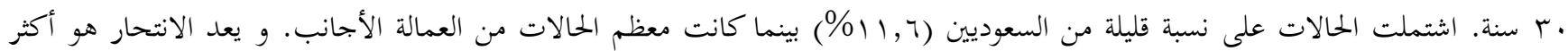

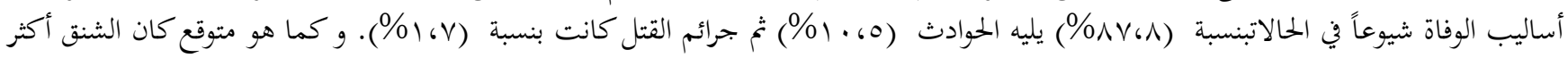

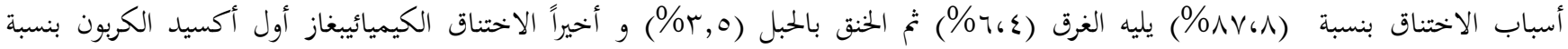

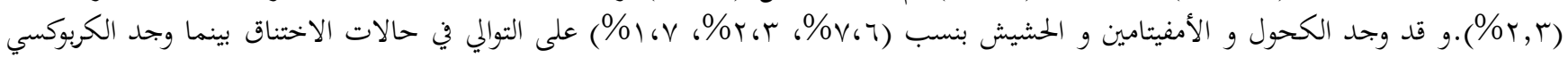

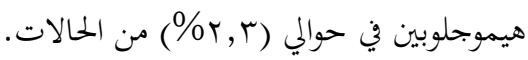

ا قسم الطب الشرعي و السموم الإكلينيكية ـ كلية الطب - جامعة المنوفية -المنوفيةـ مصر.

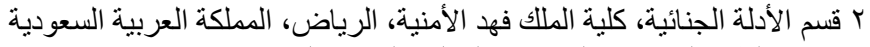

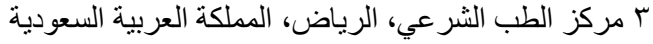

